\title{
AVALIAÇÃO DA VIABILIDADE TÉCNICA DE PRODUÇÃO DE TELHA DE FIBROCIMENTO USANDO FIBRAS ALTERNATIVAS
}

\author{
J. D. de O. HENRIQUES ${ }^{1}$, R. G. RAMBALDUCCI ${ }^{1}$, T. C. PIN $^{1}$, V. V. FRECHIANI ${ }^{1}$, F. P. \\ PUGET $^{2}$
}

${ }^{1}$ Faculdades Integradas de Aracruz, Departamento de Engenharia Química

${ }^{2}$ Instituto Federal do Espírito Santo, IFES/Aracruz

Email para contato: thaynara_coradini@hotmail.com

\begin{abstract}
RESUMO - O fibrocimento, material cimentício amplamente utilizado na construção civil, é constituído basicamente por cimento, amianto e água. Em virtude do caráter nocivo apresentado pelo amianto, estudos vêm sendo realizados para a sua substituição, utilizando fibras alternativas. O objetivo deste trabalho visa avaliar a viabilidade técnica da fabricação de telhas onduladas de fibrocimento, substituindo o amianto por duas fibras alternativas: lodo primário do tratamento de efluentes da indústria de celulose e lona vinílica. Além disso, neste estudo, parte do cimento foi substituído por lama abrasiva. As telhas foram confeccionadas usando duas composições: uma contendo $11 \%$ de lona vinílica e a outra com $11 \%$ de fibras de celulose, ambas com, $33 \%$ de cimento Portland, $11 \%$ de lama abrasiva e $45 \%$ de água. A qualidade das mesmas foi avaliada por meio de ensaios físicos e mecânico. A telha com lona vinílica, apresentou melhor desempenho nos ensaios que a amostra com fibra de celulose.
\end{abstract}

\section{INTRODUÇÃO}

Os materiais cimentícios, amplamente utilizados na construção civil, vêm superando desafios ambientais, decorrentes da geração de resíduos e da extração de recursos naturais, com a substituição de seus principais componentes por materiais reaproveitáveis.

O fibrocimento é um exemplo desse tipo de material cimentício muito utilizado na produção de telhas e caixas d'água. Em sua forma original, este era composto por cimento, amianto e água. Desde a sua descoberta, estudos vêm sendo realizados para a melhoria dos seus constituintes e propriedades. Uma das melhorias foi à adição de fibras vegetais como reforço, que proporciona às matrizes cimentícias maior resistência ao impacto, causado por maior absorção de energia e um aumento na capacidade de isolamento termo acústico (AGOPYAN e SAVASTANO,1997; ARTIGAS, 2013).

O amianto é uma fibra mineral encontrada em $2 / 3$ do solo e da água de todo o planeta, e que está presente com uma concentração de cerca de $10 \%$ em massa neste compósito cimentício com a finalidade de reforçar a matriz frágil. Apesar de ser o componente mais importante, o amianto apresenta-se como a problemática deste trabalho, pois este acarreta graves danos à saúde, impulsionando a substituição do mesmo por agregados minerais, vegetais e poliméricos (NETO, et al., 2010; ARTIGAS, 2013). 
Dessa forma, diversos materiais vêm sendo testados como alternativa ao uso de amianto. Savastano (1992) utilizou fibras vegetais de coco, sisal, e malva; Tonoli (2006) fibras proveniente do refino da polpa Kraft de sisal em conjunto com fibras de polipropileno; e Teixeira (2010) utilizou a fibra do bagaço de cana-de-açúcar.

Com base nestas informações, este trabalho vêm propor a substituição do amianto na composição de fibrocimento por dois materiais: no primeiro estudo pela lona vinílica usada, e no segundo pelo lodo primário do tratamento de efluentes da indústria de celulose. A lona vinílica é constituída basicamente de cloreto de polivinila (PVC) e de fibra de poliéster e o lodo primário do tratamento de efluentes da indústria de celulose é um resíduo rico em celulose. Além disso, é proposto a valorização da lama abrasiva oriunda do beneficiamento das rochas ornamentais nos processos de corte e polimento, avaliando a substituição parcial do cimento por este material, uma vez que o mesmo é constituído de elevado teor de sílica e alumina (que possuem características pozolânicas).

\section{MATERIAIS E MÉTODOS}

A produção das telhas foi feita com base em Savastano (2000) e Tonoli (2006) com adequações. As telhas apresentaram formato tipo onda pequena, com dimensões $200 \mathrm{~mm} \mathrm{x}$ $200 \mathrm{~mm}$ e foram feitas em triplicata para cada ensaio. As composições das telhas podem ser observadas na Tabela 1.

Tabela 1 - Composições das telhas de fibrocimento produzidas.

\begin{tabular}{cccccc}
\hline Identificação & $\begin{array}{c}\text { Cimento } \\
\text { Portland } \\
(\boldsymbol{\%})\end{array}$ & $\begin{array}{c}\text { Fibra de } \\
\text { celulose (\%) }\end{array}$ & $\begin{array}{c}\text { Lona } \\
\text { Vinílica (\%) }\end{array}$ & $\begin{array}{c}\text { Lama } \\
\text { Abrasiva } \\
(\boldsymbol{\%})\end{array}$ & Água (\%) \\
\hline Telha I & 33 & 11 & 0 & 11 & 45 \\
\hline Telha II & 33 & 0 & 11 & 11 & 45 \\
\hline
\end{tabular}

As composições de cimento, lama abrasiva e água foram mantidas constantes, de forma que se pudesse avaliar somente a influência das fibras vegetais e sintéticas no desempenho das telhas.

Os teores de fibra de celulose e de lona vinílica foram definidos como 0 e $11 \%$, pois segundo Savastano (2000), a adição de porcentagens próximas a $12 \%$ proporcionam ao produto final um melhor desempenho. Já para a lama abrasiva o teor foi definido (11\%) foi baseado no trabalho de Barbosa e Costa (2012), que obtiveram resultados satisfatórios utilizando teores de lama abrasiva de $10 \%$ e $20 \%$ em telhas de concreto.

O processo de produção das telhas iniciou-se com o preparo das matérias primas. A celulose foi triturada em moinho de facas, a lona vinílica foi degradada em liquidificador industrial e seca em estufa, e a lama abrasiva foi seca em estufa e triturada em moinho de facas. Após, esse preparo, uma mistura manual foi realizada até a obtenção de uma massa 
homogênea para a montagem das telhas em moldes de polipropileno (PP). Após a confecção, as telhas de fibrocimento seguiram para o processo de cura com duração de 28 dias, sendo que nos três primeiros dias as telhas permaneceram no molde em ambiente arejado. Em seguida, as telhas foram desenformadas e ficaram por 7 dias imersas em água e por mais 18 dias em ambiente externo e coberto.

\subsection{Ensaios Físicos e Mecânicos}

Os ensaios físicos realizados foram os de absorção de água, permeabilidade e empenamento, além do ensaio mecânico de flexão.

Absorção de água: Para este ensaio, utilizou-se a técnica de imersão (NBR 7581) baseada em Dias (2011), na qual os corpos de prova foram submersos em água por 24 horas, à temperatura ambiente. Em seguida, pesou-se a massa úmida e a massa seca (após a secagem em estufa, a $105 \pm 5^{\circ} \mathrm{C}$ por 24 horas).

Para determinação de absorção de água, utilizou-se a Equação 1:

Absorção de água $(\%)=\frac{M_{\text {umida }}-M_{\text {sera }}}{M_{\text {gara }}} \times 100$

Permeabilidade à água: Para este ensaio, foi utilizado um tubo de PVC com seção circular, reto, aberto nas extremidades, com diâmetro interno de $24,5 \mathrm{~mm}$ e altura suficiente para formar uma coluna d'água de $250 \mathrm{~mm}$ conforme sugerido por Barbosa e Costa (2012). O esquema do ensaio foi reproduzido na Figura 1. Esse aparato foi mantido por 24 horas, em ambiente coberto e ventilado. Decorrido este tempo, a face inferior da telha foi observada para verificar se houve ou não vazamento, ou formação de gotas.

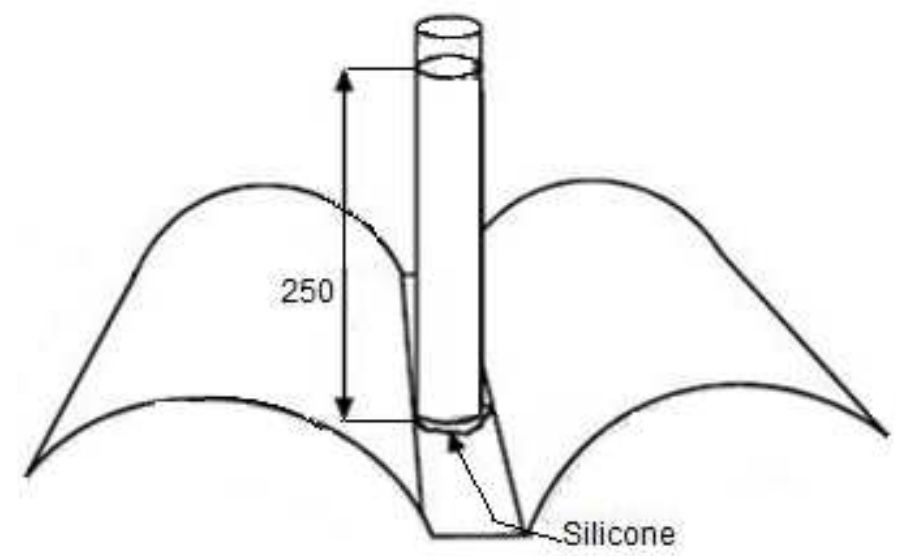

Figura 1 - Esquema do ensaio de permeabilidade. Fonte: Barbosa e Costa, 2012, com adaptações.

Empenamento: No ensaio de empenamento, o corpo de prova foi apoiado em um plano horizontal e fixado em suas extremidade para posterior medição de 6 pontos de apoio do corpo de prova em relação ao plano. Para a execução do ensaio foi utilizado um pente de 
folga da marca Cocaco, com 20 lâminas de aço $(0,05$ a $1 \mathrm{~mm})$. O empenamento foi obtido pela passagem de um pente de folga entre o corpo de prova e os pontos de apoio.

Resistência à flexão: O ensaio de flexão foi baseado em Araújo, Morais e Altides (2008) em que se determinaram a carga de ruptura e o módulo de resistência à flexão. Para a realização do teste, o corpo de prova (200 $\mathrm{mm}$ de largura e $6 \mathrm{~mm}$ de espessura) foi acondicionado por imersão em água saturada com hidróxido de cálcio, durante 24 horas à temperatura média de $5^{\circ} \mathrm{C}$, conforme descrito na norma NBR 15210-02. Este ensaio foi realizado em uma prensa hidráulica (marca Marcon, modelo MPH-15), conforme Figura 2.

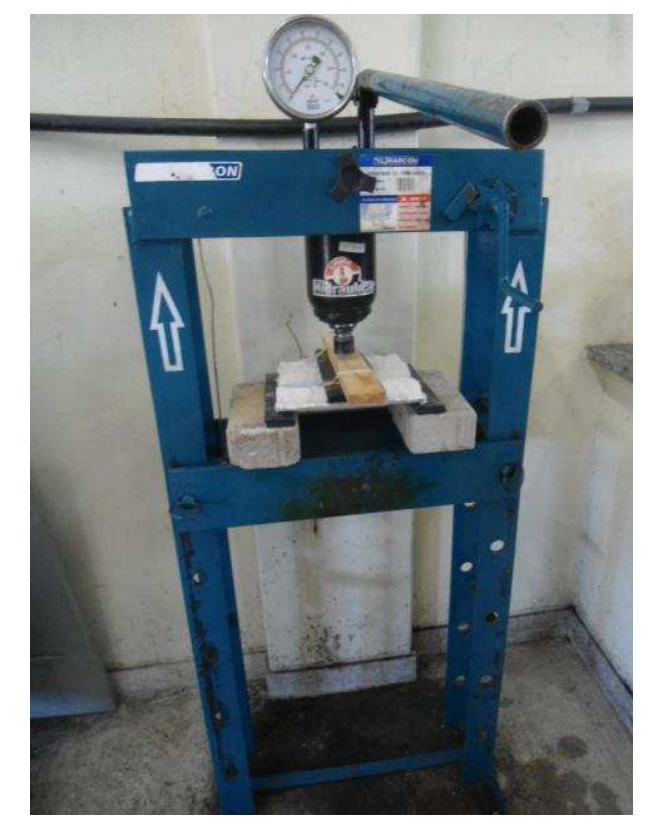

Figura 2 - Esquema do ensaio de flexão.

Fonte: Acervo pessoal.

Para a determinação dos valores de carga de ruptura e módulo de resistência a flexão, foram utilizadas as Equações 2 e 3 respectivamente.

$$
\text { Cargade ruptura }(N)=\frac{F L}{b}
$$

Onde:

F: força de ruptura $(\mathrm{N})$; L:distância entre as barras de apoio $(\mathrm{mm})$ e; b: a largura do corpo de prova $(\mathrm{mm})$.

$$
\text { Módulo de Resistência à Flexão }(\mathrm{MPa})=\frac{3 \mathrm{FL}}{2 \mathrm{be}^{2}}
$$

Onde:

e: espessura do corpo de prova (mm). 
Como os ensaios realizados para determinar a força de ruptura não foram realizados conforme estabelece a norma NBR 15210-2 os resultados obtidos não podem ser comparados com os valores estabelecidos pela mesma. Dessa forma, para que pudéssemos ter uma ideia da qualidade das telhas produzidas, comparamos os resultados obtidos para as telhas produzidas com a telha comercial da Eternit.

\section{RESULTADOS}

\subsection{Ensaios Físicos e Mecânicos}

Absorção de água

Na Tabela 2 pode ser observado que a telha I foi a que mais absorveu água, esse resultado pode estar associado ao caráter hidrofílico da celulose, que aumenta a capacidade da telha de absorver e reter água. Já a telha II absorveu menos água, podendo estar associado à característica de hidrofobicidade comum às fibras sintéticas. Experimentalmente, observa-se que a capacidade de reter a água absorvida é muito baixa, isso explica o comportamento da telha II, que mesmo com teor de $0 \%$ de celulose, ainda apresentou alto teor de absorção de água.

Tabela 2 - Resultados do teste de absorção.

\begin{tabular}{cc}
\hline Identificação & Média $\pm \boldsymbol{\delta}(\boldsymbol{\%})$ \\
\hline Telha I & $76,14 \pm 4,29$ \\
Telha II & $58,04 \pm 3,06$ \\
Telha Eternit & $26,16 \pm 1,66$ \\
\hline
\end{tabular}

De acordo com o limite estabelecido pela norma NBR 7581, telhas de fibrocimento sem amianto devem ter teor igual ou inferior a 37\%. Dessa forma, nenhum dos corpos de prova atendeu às especificações.

\section{Empenamento}

Neste ensaio, quando apoiado sobre um plano horizontal, o afastamento entre o corpo de prova e o plano não deve exceder a $3 \mathrm{~mm}$ (SAVASTANO, 2000 e BARBOSA e COSTA, 2012). Na Tabela 3, pode-se observar que as médias de empenamento em cada um dos seis pontos se apresentou abaixo do limite de $3 \mathrm{~mm}$, indicado assim um resultado satisfatório para os corpos de prova, neste ensaio. 
Tabela 3 - Média do empenamento dos corpos de prova Telha I e II.

\begin{tabular}{cc|c}
\hline Identificação & Telha I & \multicolumn{1}{c}{ Telha II } \\
\hline Pontos & \multicolumn{2}{c}{ Média $\pm \boldsymbol{\delta}(\boldsymbol{\%})$} \\
P1 & $1,0 \pm 1,73$ & $0,81 \pm 1,24$ \\
P2 & $0,58 \pm 0,66$ & $0,28 \pm 0,22$ \\
P3 & $0,250 \pm 0,43$ & $0,25 \pm 0,31$ \\
P4 & $0,38 \pm 2,46$ & $1,05 \pm 1,60$ \\
P5 & $0,33 \pm 0,57$ & $0,78 \pm 0,67$ \\
P6 & $0,53 \pm 0,79$ & $1,91 \pm 2,46$ \\
\hline
\end{tabular}

É relevante observar que ao considerar o desvio padrão, no ponto P6 das telhas II, obteve-se empenamento maior que $3 \mathrm{~mm}$. Esse resultado pode estar relacionado com o método manual de fabricação das telhas.

Permeabilidade à Água

Os resultados obtidos neste ensaio podem ser observados na Tabela 4. A amostra que apresentou o melhor resultado foi a constituída por de lona vinílica (telha II). Este resultado está associado à presença do PVC, que pode ter funcionado como material impermeabilizante. Já a telha I, que possuía um maior teor de celulose, apresentou vazamentos, comportamento associado à característica hidrofílica da celulose, permitindo uma maior absorção de água e umidade pela telha.

Tabela 4 - Verificação de vazamentos/gotas ou manchas.

\begin{tabular}{ccl}
\hline Batelada & Telha I & Telha II \\
\hline $\mathbf{1}^{\circ}$ & Mancha & Mancha \\
$\mathbf{2}^{\circ}$ & Gota/vazamento & Mancha \\
$\mathbf{3}^{\circ}$ & Gota/vazamento & Mancha \\
\hline
\end{tabular}

\section{Resistência à Flexão}

As telhas, de modo geral, tiveram uma carga de ruptura bem inferior quando comparada com a telha comercial da Eternit (Tabela 5). Este resultado pode estar associado à deformações das fibras de celulose e das micro-fraturas na parede celular desta que ocorreram na etapa de preparação da matéria-prima, em que tritura-se a celulose para padronização da sua granulometria. De acordo com Spader (2009), outro componente que pode ter contribuído para a diminuição da carga de ruptura é o percentual de lama abrasiva, já que o referido material não apresenta plasticidade. 
Tabela 5 - Carga de ruptura $(\mathrm{N})$

\begin{tabular}{cc}
\hline Identificação & Média $\pm \boldsymbol{\delta}(\boldsymbol{\%})$ \\
\hline Telha I & $0,019 \pm 4,083 \mathrm{E}-03$ \\
Telha II & $0,026 \pm 4,936 \mathrm{E}-03$ \\
Telha Eternit & $0,111 \pm 0,022$ \\
\hline
\end{tabular}

A Tabela 6 proporciona a visualização dos resultados do módulo de resistência a flexão, sendo possível verificar que os valores encontrados para os corpos de prova foram bem inferiores aos da telha comercial da Eternit. Este baixo desempenho pode estar associado à ausência de características plásticas na lama abrasiva, na celulose e na fibra de poliéster, além da existência de trincas superficiais e alta porosidade das telhas.

Tabela 6 - Módulo de resistência à flexão (Mpa).

\begin{tabular}{cc}
\hline Identificação & Média $\pm \boldsymbol{\delta}(\boldsymbol{\%})$ \\
\hline Telha I & $0,00079 \pm 1,70 \mathrm{E}-04$ \\
Telha II & $0,001117 \pm 2,06 \mathrm{E}-04$ \\
Telha Eternit & $0,004631 \pm 3,70 \mathrm{E}-03$ \\
\hline
\end{tabular}

\section{CONCLUSÕES}

Com base nos ensaios, pode-se concluir que a telha II apresentou melhor desempenho nos testes de flexão e de permeabilidade. Já a telha I, foi aprovada somente no teste de empenamento, ficando abaixo do limite de afastamento, de $3 \mathrm{~mm}$. Por fim, no teste de absorção, as telhas de fibrocimento produzidas apresentaram teores superiores a $37 \%$, ficando acima do aceitável para comercialização.

As análises realizadas e os resultados obtidos neste trabalho mostram que, usando as composições estudadas, a produção de telhas onduladas de fibrocimento como uma alternativa de substituir o amianto pela lona vinílica e pelo lodo primário da indústria de celulose não permite alcançar todas as exigências da legislação.

\section{REFERÊNCIAS}

ABNT, Associação Brasileira de Normas Técnicas. NBR 7581, Telha ondulada de fibrocimento, 1993.

ABNT, Associação Brasileira de Normas Técnicas. NBR 15210-2, Telha ondulada de fibrocimento sem amianto e seus acessórios - parte 2: ensaio, 2005.

AGOPYAN, V.; SAVASTANO., H. Jr. Uso de materiais alternativos à base de fibras vegetais na construção civil: Experiência Brasileira. Seminário Ibero americano de materiais fibro reforçados. Universidad del Valle, Cali, Colômbia, 1997. P. 23-40. (Artículo 03). 
ARTIGAS, L. V. Fibrocimento. Materiais de construção III, Universidade Federal do Paraná. Curitiba, 2013.

BARBOSA, J. F.; COSTA, V. S. Avaliação da utilização de lama abrasiva do beneficiamento de mármore e granito na confecção de telhas de concreto. Trabalho de Conclusão de Curso. Tecnologia em Saneamento Ambiental, Instituto Federal do Espírito Santo, Vitória, 2012.

DIAS, C. M. R. Fibrocimentos com graduação funcional. Tese, Engenharia de Construção Civil e Urbana - USP, São Paulo, 2011.

ETERNIT. Eternit S.A., 2003. Eternit, 2003. Disponível em:<http://www.eternit.com.br>. Acesso em: 10 maio 2013.

ISAIA, G. C. Materiais de construção civil e Princípios de Ciência e Engenharia de Materiais. IBRACON. São Paulo, 2007. Vol. 2, páginas 983 à 1006.

NETO, A. H. A.; GOMES, A. B. V.; SOUZA, A. M. M.; SOUZA, D. C. L.; SÁ, I. R.; LIMA, L. R. M.; LIMA, P. T. M. Coberturas: Cobertura Fibrocimento. Centro Universitário do Maranhão, São Luís, 2010.

REDDY, J.N. Mechanics of Laminated Composite Plates: theory and analysis, CRC Press, Inc., ISBN 0-8493-3101-3. 1997.

SAVASTANO, H. Jr. Zona de transição entre fibras e pasta de cimento Portland: Caracterização e inter-relação com as propriedades mecânicas do compósito. Tese, Engenharia de Construção Civil e Urbana. Universidade de São Paulo, São Paulo,1992.

SAVASTANO, H. Jr. Materiais a base de cimento reforçados com fibra vegetal: Reciclagem de resíduos para a construção de baixo custo. Tese, Departamento de Engenharia de Construção Civil. Universidade de São Paulo, São Paulo, 2000.

SPADER, R. Z. Introdução de novos materiais em massas de telhas cerâmicas. Curso de tecnologia em Cerâmica. Universidade do Extremo Sul Catarinense, Criciúma, 2009.

TEIXEIRA, R. S. Utilização de resíduos sucro-alcooleiros na fabricação de fibrocimento pelo processo de extrusão. Dissertação, Ciências e Engenharia de Materiais. Universidade de São Paulo, São Carlos, 2010.

TONOLI, G. H. D. Aspectos produtivos e análise de desempenho do fibrocimento sem amianto no desenvolvimento de tecnologia para telhas onduladas. Dissertação, Faculdade de Zootecnia e Engenharia de Alimentos. Universidade de São Paulo, Pirassununga, 2006. 